\title{
Building a Cost Effective Network for E-learning in Developing Countries
}

\author{
Edem E. Williams (Corresponding author) \& Essien Eyo \\ University of Calabar, Calabar, Nigeria \\ E-mail: edemwilliam@yahoo.com, essieneyo@gmail.com
}

\begin{abstract}
E-learning has started to make way into developing countries and is believed to have huge potential for governments struggling to meet a growing demand for education while facing an escalating shortage of teachers and other educational infrastructure. E-learning is seen as a tool for raising the number of students who have access to higher education, especially marginalized groups in rural areas, by being a cheaper and more flexible alternative. Among several challenges are the costs of providing, installing and managing e-learning hardware infrastructure. This paper is set to build a network model that will conserve bandwidth, will stream audio and video rapidly and at the same time require minimal administration. This means that high speed communication/data access can be achieved at the lowest possible cost, thereby enhancing e-learning.
\end{abstract}

Keywords: E-learning, Teleconferencing, Server catching, Bandwith, Data access

\section{Introduction}

As communication technologies and the Internet continue to merge, organizations continue to integrate them within their activities and corporate practices. One of the key benefits of such integration includes learning and curriculum development; which is otherwise referred to as e-learning. Because of the trend toward globalization of research and development, there exists the need for uniform and customized training. E-learning is becoming increasingly prominent in tertiary education, with universities increasing provision and more students signing up. But is it actually changing the way universities teach and students learn, or is it simply a case of students typing up their essays on computers and professors sending them course reading lists or work assignments by e-mail? The vision common at the height of the dot.com boom of students following entire courses at a prestigious overseas university from the comfort of their own home, without the inconvenience and cost of living abroad for years has largely failed to materialise. Students are still mostly wedded to classrooms for at least part of the time, and after the hype of the new economy, growing disenchantment with e-learning has replaced earlier over-enthusiasm. E-learning is seen as a tool for raising the number of students who have access to higher education, especially marginalized groups in rural areas, by being a cheaper and more flexible alternative (Dhanarajan, 2001; Potashnik and Caper,1998; patton,2000). Challenges are however plentiful; in many developing countries where there is a lack of vital e-learning components such as computers' electricity and skills (Dhanarajah, 2001; Heeeks, 2002; Rajesh, 2003).

For e-learning to succeed in the developing world, it needs to build on another important pillar: the existence of infrastructure, along with some degree of connectivity. However, important technical constraints have to be overcome. The most common encountered are issues such as unreliable Internet connection and phone lines, slow access to web sites due to narrow bandwidth and limited numbers of computers connected to the Internet. Therefore, a key challenge is that technological requirements must be kept to a minimum in order to increase the participation of developing countries in e-learning (Marc Sehrt, 2003).

\section{Survey of E-Learning in Africa}

Survey of e-learning in Africa was based on 316 responses to a questionnaire circulated in 2007 to people on the e-Learning Africa database(Unwin, 2008). This represents approximately 4\% of people on the database, and is likely to reflect those who are already most committed to the use of e-learning within Africa. Respondents to the survey were from 42 different African countries, with Kenya (15\%), South Africa (12\%), Nigeria (11\%), Ethiopia (9\%) and Uganda (8\%) furnishing most respondents. Of those providing details of their gender, $25 \%$ (77 3) were women and 75\% (230) were men. Of those who reported an educational context within which they were working, $118(37 \%)$ were from higher education institutions, $16(5 \%)$ from primary or secondary schools, $14(5 \%)$ from NGOs, and $9(3 \%)$ from vocational and technical institutions.

These respondents provided a wide variety of information about their e- learning practices, and it is difficult to draw generalizations based on the evidence provided. Nevertheless, three main conclusions can be drawn: 
- There is a wide variety of different e-learning practices in Africa.

- E-learning is still very much in infancy across most of the continent, and

- There is much enthusiasm amongst respondents for developing the potential of e-learning in their countries.

However, respondents also identified key constraints in seeking to implement and develop e-learning strategies and practices, including the lack of infrastructure (particularly connectivity, and especially in rural areas), the need for appropriate training and capacity development, a lack of relevant digital content, and the cost of implementation. The following findings were made concerning e-learning in Africa:

To make e-learning more effective, many suggestions were received from respondents' countries as to things that would make e-learning more effective. Among the most frequently mentioned were:

- Availability of hardware (particularly computers)

- Faster internet connectivity/improved bandwidth

- Improved software

- Appropriate policies favoring e-learning

- Provision of technical support for e-learning at a range of scales

- Lower prices for connectivity

- Availability of reliable electricity

- Appropriate content in appropriate languages

- Awareness raising about the value of e-learning

- Improved training for teachers in e-learning

\section{Cost Effective Network Design}

Cost effective network is a network that can be implemented and maintained at minimal cost, taking into consideration network efficiency and effective bandwidth utilization. Figure 6 shows such a design.

\section{Fibre Optic Cabling}

Most companies use fibre for economic reasons, but their cost justification requires adopting new network architectures to take advantage of fibre's strengths. A properly designed premises cabling network can also be less expensive when done in fibre instead of copper. The following are instances of fibre optic being less expensive than copper.

\section{Industrial Networks}

In an industrial environment, Electromagnetic Interference (EMI) is often a big problem. Motors, relays, welders and other industrial equipment generate a tremendous amount of electrical noise that can cause major problems with copper cabling, especially unshielded cable like Cat 5. In order to run copper cable in an industrial environment, it is often necessary to pull it through conduit to provide adequate shielding. With fibre optics, one has complete immunity to EMI. One only needs to choose a cable type that is rugged enough for the installation, with breakout cable being a good choice for it's heavy-duty construction. The fibre optic cable can be installed easily from point to point, passing right next to major sources of EMI with no effect. Conversion from copper networks is easy with media converters, gadgets that convert most types of systems to fibre optics. Even with the cost of the media converters, the fibre optic network will be less than copper run in conduit.

\section{Long Cable Runs}

Most networks are designed around structured cabling installed per EIA/TIA 568 standards. This standard calls for 90 meters (295 feet) of permanently installed unshielded twisted pair (UTP) cable and 10 meters (33 feet) of patchcords. But suppose one needs to connect two buildings or more? The distance often exceeds the 90 meters by the time one includes the runs between the buildings plus what one needs inside each building. By the time one buys special aerial or underground waterproof copper cable and repeaters, one will usually spend more than if one bought some outside plant Fibre optic cable and a couple of inexpensive media converters. It is guaranteed cheaper if one goes more than two links (180 meters.) 


\section{Centralised Fibre LANs}

When most contractors and end users look at fibre optics versus Cat 5e cabling for a LAN, they compare the same old copper LAN with Fibre directly replacing the copper links. The fibre optic cable is a bit more expensive than Cat $5 \mathrm{e}$ and terminations are a little more too, but the big difference is the electronics which are $\$ 200$ or more per link extra for fibre. However, the real difference comes if one uses a Centralised Fibre optic network - shown on Figure 7 below.

Since fibre does not have the 90 meter distance limitation of UTP cable, one can place all electronics in one location in or near the computer room. The telecom closet is only used for passive connection of backbone fibre optic cables, so no power, UPS, ground or air conditioning is needed. These auxiliary services, necessary with Cat 5 hubs, cost a tremendous amount of money in each closet. In addition, having all the fibre optic hubs in one location means better utilisation of the hardware, with fewer unused ports. Since ports in modular hubs must be added in modules of 8 or 16, it is not uncommon with a hub in a telecom closet to have many of the ports in a module empty. With a Centralised Fibre System, one can add modules more efficiently as one is supporting many more desktop locations but need never have more than one module with open ports.

\section{High Speed Networking}

It was over a year after Gigabit Ethernet $(\mathrm{GbE})$ became available on fibre optics that it finally became available on $\mathrm{Cat} 5 \mathrm{e}$. It took another couple of years before $\mathrm{GbE}$ on copper became significantly less expensive. In order to get $\mathrm{GbE}$ to work over Cat $5 \mathrm{e}$, the electronics must be very complicated, and consequently as expensive as fibre. A newer version is in the wings, awaiting a Cat 6 standard, but that means the version running over Cat $5 \mathrm{e}$ will be obsolete before it even gets started.

Finally, when it comes to costs, looking at the cabling component costs may not be a good way to analyse total network costs. Consider the total system and one may find fibre looks a lot more attractive because of the following:

- SPEED: Fiber optic networks operate at high speeds - up into the gigabits

- BANDWIDTH: large carrying capacity

- DISTANCE: Signals can be transmitted further without the need to "refresh" or strengthened.

- RESISTANCE: Greater resistance to electromagnetic noise such as radios, motors or other nearby cables.

- MAINTENANCE: Fiber optic cables costs much less to maintain (Marc Sehrt, 2003).

\section{Server Caching Technology}

A cache server is a dedicated network server or service acting as a server that saves Web pages or other Internet content locally. By placing previously requested information in temporary storage, or cache, a cache server both speeds up access to data and reduces demand on an enterprise's bandwidth. Cache servers also allow users to access content offline, including rich media files or other documents. A cache server is sometimes called a "cache engine."A cache server is almost always also a proxy server, which is a server that "represents" users by intercepting their Internet requests and managing them for users. Typically, this is because enterprise resources are being protected by a firewall server. That server allows outgoing requests to go out but screens all incoming traffic. A proxy server helps match incoming messages with outgoing requests. In doing so, it is in a position to also cache the files that are received for later recall by any user. Server caching can speed dynamic pages to near-static speeds. Caching web pages frees up bandwidth for real-time, on-line video conferencing needed for e-learning (Sullivan, 1999).

\section{Value Addition to E-Learning}

- Use of Optical fibre cabling ensures:

o Cost saving

o Fast video streaming

o Bandwidth conservation

- Server caching technology

- Conserves bandwidth for video conferencing

- Ensures fast access to web pages

- Reduce network treats 
- Centralised v-sat equipment

o Saves cost of multiple subscription

\section{Conclusion}

While the move toward globalizing e-learning is driven by the need to reduce educational cost, and the drive to improve efficiency (Pargman, 1998; Sproull and Kiesley, 1991). it has been found that efficiency and cost advantage showed no significant predictive value on usage, or social or cultural effects once technologies have been deployed (Pargman, 1998).

There is a correlation between Internet usage and global learning penetration and adoption in any given society. For instance, when the number of Internet users is compared with actual population figure, it reveals that there are still a lot of potential users to reach (Barron, 2000). The lack of technological infrastructure could derail any e-learning program regardless of how lofty its goal might be. In addition to how different cultures use or react to different technology media, certain infrastructure, such as high speed Internet access, are simply not commonplace elsewhere around the globe.

\section{References}

Barron, T. (2000). E-learning's global migration. Retrieved on August 262005 from http://www.learningcircuits.org/2000/Sep2000/barron .html.

Dhanarajan, G. (2001). Distance Education: Promise, Performance and Potential, Open Learning, 16, 1, 61-68. http://pdfserve.informaworld.com/106451_75042609 9_713688418.pdf

Heeks, R. (2002). Information Systems and Developing Countries: Failure, Success and Local Improvisations, The Information Society, 18, 2, 101112. [Online] available: http://pdfserve.informaworld.com/167133_75042609 9_713856778.pdf

Marc Sehrt. (2003). Digital divide into digital opportunities: E-learning in the developing countries UN Chronicle, [Online] available: http://www.vdvworks.com/

Pargman, D. (1998). 'Reflections on cultural Bias and adaptation'. In C. Ess and F. Sudweeks (eds.). Cultural attitudes towards communication and technology, Australia: University of Sydney, pp.73-91.

Patton, M.A. (2000). The Importance of Being Flexible with Assignment Deadlines, Higher Education in Europe, 25, 3, 417-423.

Potashnik, M. and Capper, J. (1998). Distance Education: Growth and Diversity, Finance \& Development, 35, 1, 42-45. [Online] available: http://www.worldbank.org/fandd/english/pdfs/0398/0110398.pdf

Rajesh, M. (2003). A Study of the Problems Associated with ICT Adaptability in Developing Countries in the Context of Distance Education, The Turkish Online Journal of Distance Education, 4, 2: [Online] available: http://tojde.anadolu.edu.tr/tojde10/articles/Rajesh.htm

Sproull, L., and Kiesler, S. (1991). Connections: New ways of working in the networked organization. Cambridge, MA: MIT Press.

Sullivan, C. (1999). Optical Fiber: Coming in from the Cold. fotec, Inc. Aug 1, 1999 12:00 PM. [Online] available: www.fibre-optics.info/glossary-a

Unwin, T. (2008). Survey of e-learning in Africa. [Online] available: http:/www.comminit.com/en/node 


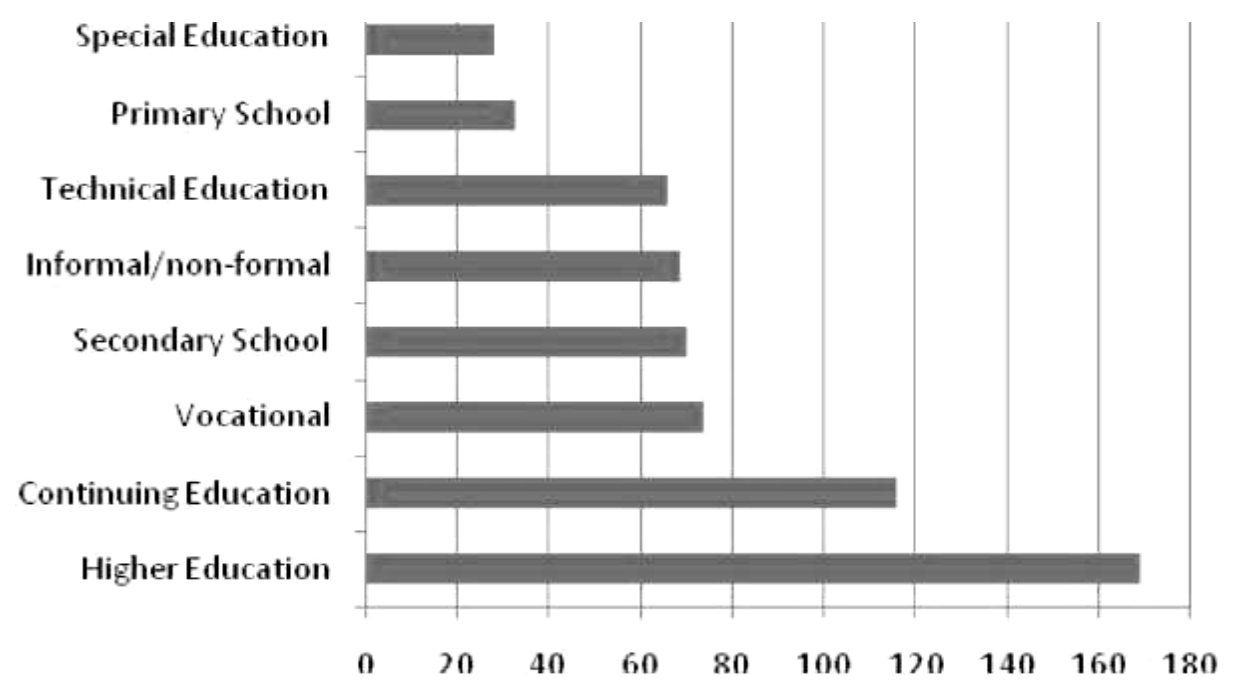

Figure 1. Types of Courses offered by e-learning in Africa



Figure 2. The value of e-learning 


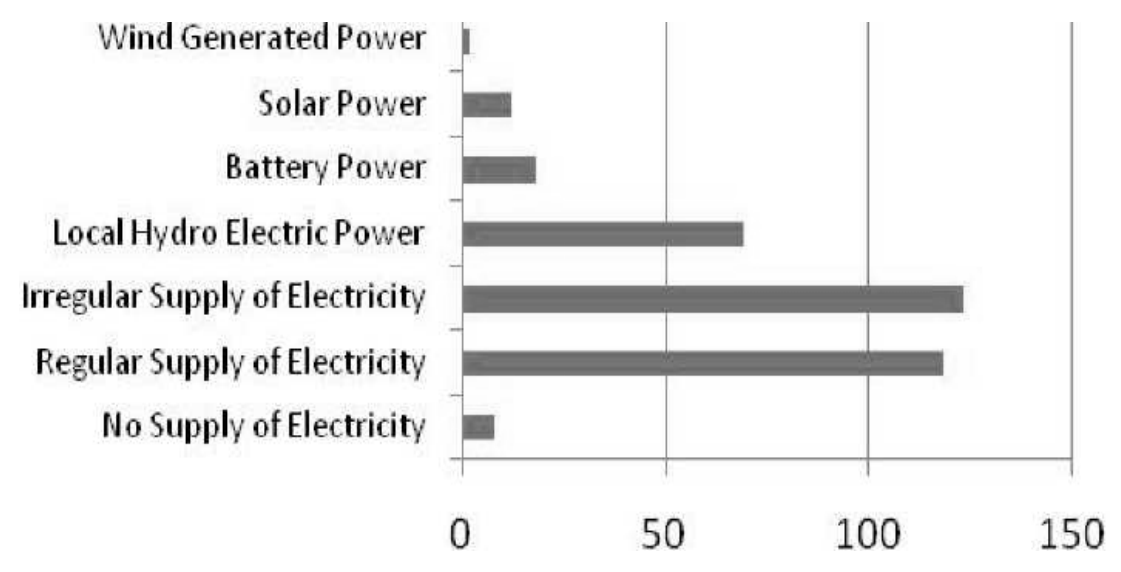

Figure 3. Available Power Source

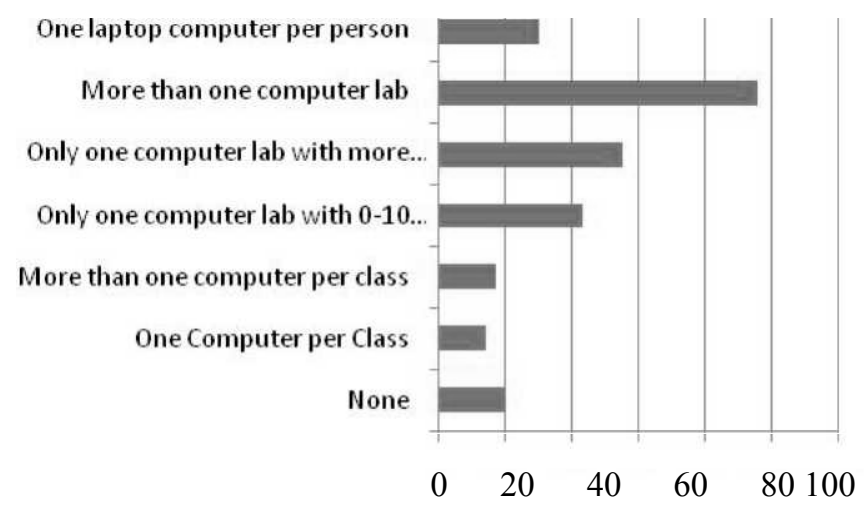

Figure 4. Availability of Computers

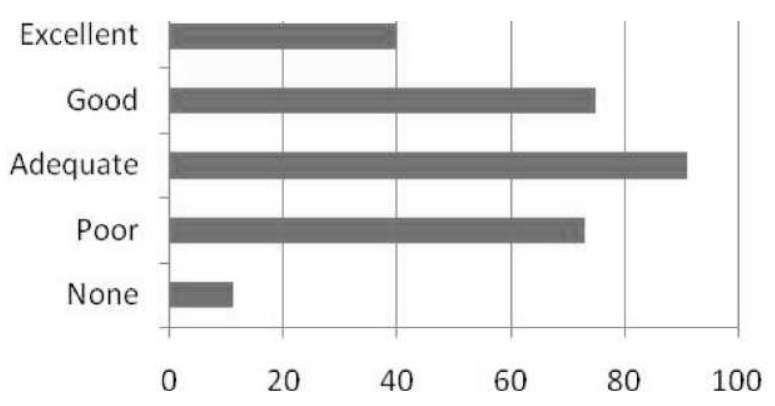

Figure 5. Internet Connectivity 


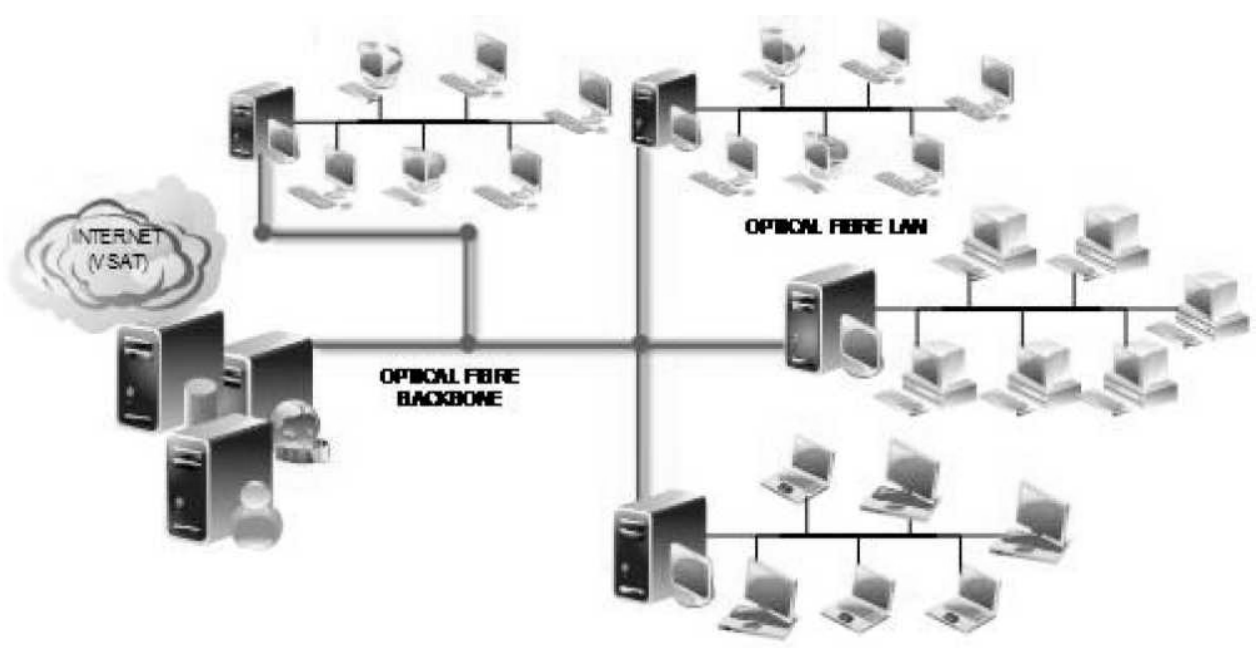

Figure 6. Cost Effective Network Design

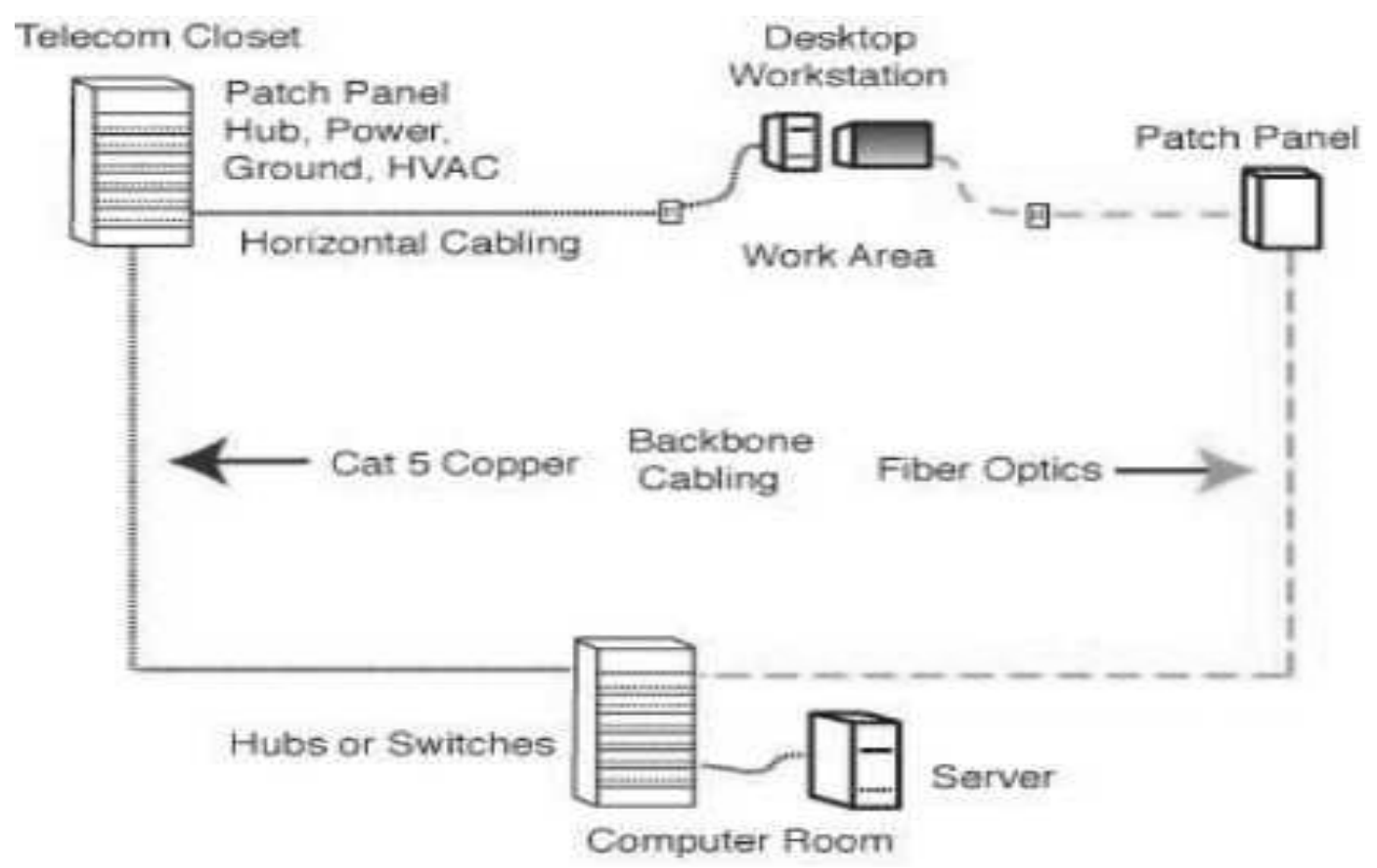

Figure 7. Centralized Fibre Optic Network 